\title{
Mastoid Exploration in the Management of Chronic Otitis Media with Complications
}

\author{
Viswanatha Borlingegowda* \\ Professor and Head, Department of ENT, Bangalore Medical College\& Research Institute, India \\ *Corresponding author: Viswanatha Borlingegowda, Professor and Head, Department of ENT, Bangalore Medical College\& Research \\ Institute, Bangalore, India
}

\begin{abstract}
Chronic suppurative otitis media is a common problem in developing countries. Complications due to chronic suppurative otitis media still pose a major problem in the developing countries. In cases of chronic suppurative otitis media associated with complications, after managing the complications, mastoid exploration should be done to remove the primary source of infection. Planning of mastoid exploration play an important role in the management. Here the management of primary otogenic septic foci, after the management of extracranial and intracranial complications is discussed.
\end{abstract}

Keywords: Mastoid exploration; otitis media; complications

\section{Introduction}

Chronic suppurative otitis media, infection of the middle ear cleft, is still a common disease in the developing countries. The complications associated with it, especially intra cranial, still pose a major problem in the developing countries. The anatomical proximity of the middle ear cleft and mastoid air cells to the extracranial and intracranial compartments places structures located in these areas at increased risk of infectious complications [1]. Majority of the intra cranial are seen more in the rural population than in urban population. Its incidence is decreased since the introduction of antibiotics, but the problem still exists. Complications due to chronic suppurative otitis media remain a serious concern, particularly in developing countries. Chronic suppurative otitis media is classified into squamous and mucosal types. The complications of chronic suppurative otitis media are classified into extracranial complications and intracranial complications [1,2]. Complications are more common in patients having squamous type otitis media than in patients with mucosal type of otitis media. Many studies have shown that vast majority of subjects who had complications due to chronic suppurative otitis media were found to have cholesteatoma [3-8].
Complications of Chronic Otitis Media Are Classified as Follows

\section{Extracranial complications}

a) Subperiosteal mastoid abscess

b) Mastoiditis

c) Post aural fistula

d) Facial nerve palsy

e) Labyrinthine fistula

f) Petrositis

\section{Intracranial complications}

a) Cerebral abscess

b) Cerebellar abscess

c) Lateral sinus thrombosis

d) Otitic hydrocephalus 
e) Meningitis

f) Subdural abscess

g) Extradural abscess

The incidence of extracranial and intracranial complications of chronic suppurative otitis media and cholesteatoma has decreased with the advent of new antibiotics late in the twentieth century. However, these complications still occur, and can be lethal if they are not identified and managed properly. With the continued development of multi-drug-resistant pathogens and immunocompromised diseases, these complications may again become more prevalent as our current antibiotics become less effective [1].

For an Otologist it is important to review the changing trends in presentation of the disease and its complications in order to understand and instill the most appropriate management for the same.

\section{Materials and Methods}
A. Study type: Prospective study.
B. Study design: Descriptive study.
C. Sample size: 81

This was a prospective descriptive study done in a medical College hospital. In the present study there were 81 patients with 124 complications. All cases of squamous ear disease with complications only were included in this study. All these patients underwent microscopic ear examination, ear swab for culture and sensitivity and high-resolution CT scan of the temporal bone. Histopathological examination of the middle ear cholesteatoma/ granulation tissue was also done in all the cases. Patients were started on combination of broad-spectrum antibiotics. Antibiotics were changed according to culture and sensitivity report in required cases. Patients with extracranial complications underwent early mastoid exploration. In patient with mastoid abscess, abscesses were also drained, and mastoid exploration was performed later. In patients with intracranial complications, neurosurgical intervention was done first. Mastoid exploration was planned as

soon as the general condition of the patient improved. Surgical clearance of sigmoid sinus thrombosis through the transmastoid route was undertaken immediately. All patients underwent canal wall down mastoidectomy. All the patients were followed up for minimum period of three months.

\section{Statistical software}

The Statistical software namely SAS 9.2, SPSS 15.0, Stata 10.1, MedCalc 9.0.1,Systat 12.0 and R environment ver.2.11.1 were used for the analysis of the data. Microsoft word and Excel have been used to generate tables etc. Chi-square/ Fisher Exact test has been used to find the significance of study parameters on categorical scale between two or more groups.

\section{Observations and results}

In this study there were 81 patients with squamous type of chronic otitis media with complications. Number of patients are 81 but complications are 124 .This is because few patients had more than one complication. There were 69 extracranial complications and 55 intracranial complications. The incidences of extracranial complications were more than the incidences of intracranial complications. The commonest extracranial complication was subperiosteal mastoid abscess and the commonest intracranial complication was brain abscess. Age of the patients ranged from 5 years to 65 years. Most of the complications occurred below the age of 20 years [Table 1]. Correlation of extracranial and intracranial complications according to age showed that facial palsy was more common in age below 20 years ( $\mathrm{p}$ value $0.012^{*}$ ), labyrinthine fistula is more common between 20 to 40 years of age ( $p$ value $0.054+$ ) and cerebellar abscess is more common in age below 20 years ( $p$ value $0.095+$ ) and it was significant [Table 2].

Table 1: Showing age distribution of the patient.

\begin{tabular}{|c|c|c|}
\hline Age in Years & Number of Patients & \% \\
\hline$<20$ & 39 & 48.1 \\
\hline $21-40$ & 28 & 34.6 \\
\hline $41-60$ & 12 & 14.8 \\
\hline$>60$ & 2 & 2.5 \\
\hline Total & 81 & 100 \\
\hline
\end{tabular}

Table 2: Showing Correlation of extracranial and intracranial complications according to the age.

\begin{tabular}{|c|c|c|c|c|c|}
\hline \multirow{2}{*}{ Complications } & \multicolumn{4}{|c|}{ Age in Years } & \multirow{2}{*}{$P$ value } \\
\hline & $<20(n=39)$ & $21-40(n=28)$ & $41-60(n=12)$ & $>60(n=2)$ & \\
\hline \multicolumn{6}{|c|}{ Extracranial } \\
\hline Subperiosteal mastoid abscess & $10(25.6 \%)$ & $9(32.1 \%)$ & $3(25 \%)$ & $1(50 \%)$ & 0.763 \\
\hline Mastoiditis & $3(7.7 \%)$ & $3(10.7 \%)$ & $2(16.7 \%)$ & $0(0 \%)$ & 0.685 \\
\hline Post aural fistula & $4(10.3 \%)$ & $6(21.4 \%)$ & $2(16.7 \%)$ & $0(0 \%)$ & 0.589 \\
\hline Facial nerve palsy & $5(12.8 \%)$ & $3(10.7 \%)$ & $4(33.3 \%)$ & $2(100 \%)$ & $0.012^{*}$ \\
\hline Labyrinthine fistula & $1(2.6 \%)$ & $5(17.9 \%)$ & $2(16.7 \%)$ & $0(0 \%)$ & $0.054+$ \\
\hline Petrositis & $4(10.3 \%)$ & $0(0 \%)$ & $0(0 \%)$ & $0(0 \%)$ & 0.279 \\
\hline
\end{tabular}




\begin{tabular}{|c|c|c|c|c|c|}
\hline \multicolumn{6}{|c|}{ Intracranial } \\
\hline Temporal lobe abscess & $10(25.6 \%)$ & $4(14.3 \%)$ & $2(16.7 \%)$ & $1(50 \%)$ & 0.397 \\
\hline Cerebellar abscess & $8(20.5 \%)$ & $1(3.6 \%)$ & $0(0 \%)$ & $0(0 \%)$ & $0.095+$ \\
\hline Occipital lobe abscess & $1(2.6 \%)$ & $0(0 \%)$ & $0(0 \%)$ & $0(0 \%)$ & 1 \\
\hline Lateral sinus thrombosis & $8(20.5 \%)$ & $4(14.3 \%)$ & $0(0 \%)$ & $0(0 \%)$ & 0.39 \\
\hline Otitic hydrocephalus & $6(15.4 \%)$ & $2(7.1 \%)$ & $0(0 \%)$ & $0(0 \%)$ & 0.512 \\
\hline Meningitis & $3(7.7 \%)$ & $1(3.6 \%)$ & $0(0 \%)$ & $0(0 \%)$ & 0.832 \\
\hline Subdural abscess & $3(7.7 \%)$ & $0(0 \%)$ & $0(0 \%)$ & $0(0 \%)$ & 0.43 \\
\hline Extradural abscess & $0(0 \%)$ & $1(3.6 \%)$ & $0(0 \%)$ & $0(0 \%)$ & 0.519 \\
\hline
\end{tabular}

+ Suggestive significance ( $\mathrm{P}$ value: $0.05<\mathrm{P}<0.10)$

* Moderately significant (P value: $0.01<\mathrm{P}<0.05$ )

** Strongly significant (P value: $\mathrm{P}<0.01$ )

\section{Otogenic complications}

The incidence of extracranial complications was more than intracranial complications. The commonest extracranial complication was subperiosteal mastoid abscess and the commonest intracranial complication was brain abscess. Brain abscess was the commonest intracranial complication followed by lateral sinus thrombosis [Table 3].

Table 3: Showing Otogenic extracranial and intracranial complications.

\begin{tabular}{|c|c|c|c|c|}
\hline Complication & Right & Left & Total & \% \\
\hline $\begin{array}{c}\text { Subperiosteal } \\
\text { mastoid abscess }\end{array}$ & 11 & 12 & 23 & 18.54 \\
\hline Mastoiditis & 2 & 6 & 8 & 6.45 \\
\hline Post aural fistula & 6 & 6 & 12 & 9.67 \\
\hline Facial nerve palsy & 8 & 6 & 14 & 11.29 \\
\hline Labyrinthine fistula & 4 & 4 & 8 & 6.45 \\
\hline Petrositis & 2 & 2 & 4 & 3.22 \\
\hline $\begin{array}{c}\text { Temporal lobe } \\
\text { abscess }\end{array}$ & 9 & 8 & 17 & 13.7 \\
\hline Cerebellar abscess & 3 & 6 & 9 & 7.25 \\
\hline $\begin{array}{c}\text { Occipital lobe } \\
\text { abscess }\end{array}$ & 0 & 1 & 1 & 0.8 \\
\hline $\begin{array}{c}\text { Lateral sinus } \\
\text { thrombosis }\end{array}$ & 6 & 6 & 12 & 9.67 \\
\hline Otitic hydrocephalus & -- & -- & 8 & 6.45 \\
\hline Meningitis & -- & -- & 4 & 3.22 \\
\hline Subdural abscess & 0 & 3 & 3 & 2.41 \\
\hline Extradural abscess & 1 & 0 & 1 & 0.8 \\
\hline \begin{tabular}{c} 
Total \\
\hline
\end{tabular} & 52 & 60 & 124 & \\
\hline
\end{tabular}

\section{Surgical treatment}

Patients with extracranial complications underwent immediate mastoid exploration. In patients with mastoid abscess, abscesses were also drained, and mastoid exploration was performed later. In patients with intracranial complications, neurosurgical intervention was done first. Mastoid exploration was planned as soon as the general condition of the patient improved. Patients underwent mastoidectomy surgery between 2 to 9 days. Surgical clearance of sigmoid sinus thrombosis through the transmastoid route was undertaken immediately. All patients underwent canal wall down mastoidectomy. The entire patients were followed up for minimum period of three months. Patient with intracranial complication underwent neurosurgical intervention first (except three patients with small abscess in the temporal lobe) and later they underwent mastoid exploration. The neurosurgical interventions included craniotomy and abscess excision, craniectomy and abscess excision, burr hole and ventriculo peritoneal shunt procedure.

All patients in the study underwent canal wall down mastoidectomy of which 49 underwent concurrent tympanoplasty as well. After 3 months following surgery, 62(76.5\%) patients had dry mastoid cavity and $19(23.5 \%)$ patients' mastoid cavity was wet.

\section{Discussion}

The complications of chronic suppurative otitis media are classified into extracranial complications and intracranial complications. Complications are more common in patients having squamous type otitis media than in patients with mucosal type of otitis media. When there is a suspicion of intracranial complication, a contrast CT scan or MRI must be done while intravenous antimicrobial therapy is initiated. Radiological studies are the most useful diagnostic tools in detecting and localizing early abscesses. MRI gives better information about the abscess than CT scan, but CT scan is preferred because it gives detailed information about bony erosion of the mastoid, and can help in determining the etiology of the abscess and helps in the most appropriate surgical treatment options [1,9]. The treatment of choice for brain abscess is neurosurgical drainage. Patient must be stabilized before neurosurgical intervention. Neurosurgical drainage is performed, either through an open craniotomy with drainage or excision, or by stereotactic aspiration through a burr hole. After neurosurgical intervention, mastoidectomy should be done to remove the source 
of infection. The appropriate time to perform the mastoidectomy is controversial [1]. Murthy et al. [9] stated that first neurosurgical drainage and later ear operation should be done. Morwani et al. [10] stated that single stage, transmastoid approach to both the chronic ear infection and the intracranial abscess is a safe and effective treatment strategy to decrease the mortality and morbidity arising from this pathology. Syal et al. [11] recommend that transmastoid drainage of pus can successfully treat mastoid disease and brain abscess with single surgical intervention. Sinha et al. [12] are of the opinion that endoscopic aspiration of brain abscess is a safe and effective alternative method of treatment. It has been conventional teaching that a mastoidectomy is performed in a delayed manner after the patient recovers from the abscess and neurosurgical drainage. Current recommendations, however, are to perform a mastoidectomy at the time of abscess drainage to remove the infectious focus, assuming the patient is stable enough to tolerate this additional surgery [1].

According to Kurien et al. [13], craniotomy with concurrent mastoidectomy is not only safe, but also removes the source of infection at the same time the complication is being treated, thus avoiding reinfection while the patients awaiting the ear surgery. In addition, the treatment is completed in single, shorter stay, which is beneficial for the patient. In the present study there were 17 cases of temporal lobe abscess, one case of occipital lobe abscess and 9 cases of cerebellar abscess. Except in three cases of temporal lobe abscess (abscess size less than $1.6 \mathrm{cms}$ ), all patients underwent neurosurgical intervention for the management of brain abscess. All the patients who underwent neurosurgical drainage of the brain abscess underwent canal wall down mastoidectomy as soon as they recovered from the abscess and neurosurgical drainage. There were no complications during the waiting period. Early mastoidectomy following neurosurgical drainage of the brain abscess is found to be effective in this study. However, specific parameters dictating staged versus simultaneous surgery have not yet been reported or established in the literature. Morwani et al. [10] are of the opinion that there is a role for conservative management of brain abscess which are smaller than $1 \mathrm{~cm}$ in diameter, with intravenous antibiotics and follow-up CT scans, together with eradication of otogenic septic focus at the earliest stage. They also stated that same concept holds well in the treatment of tiny residual abscess. In the present study all three patients with small temporal lobe abscess started showing clinical improvement with the commencement of intravenous antibiotics and serial CT scan did not show any increase in abscess size. Neurosurgical intervention was not required. All the three patients underwent canal wall down mastoidectomy. They responded well to medical management. Antibiotic therapy was continued for 6 weeks and post treatment CT scan showed abscess resolution. This study showed that small otogenic brain abscess, which were less than $1.6 \mathrm{~cm}$ in size responded to treatment with antibiotics and could be managed by medical therapy. Surgery was required only for the management of atticoantral ear disease. Close collaboration between otologist, neuroradiologists, and neurosurgeons, as well as adequate surgical interventions and appropriate antimicrobial therapy, remain the cornerstones of effective medical management of small brain abscess secondary to atticoantral ear disease.

In the present study patients with intracranial complications first underwent neurosurgical intervention (except three patients with small temporal lobe abscess) and later underwent surgery for atticoantral disease. Patients with the diagnosis of lateral sinus thrombosis underwent surgery immediately. Other patients underwent surgery between 2 to 9 days. Patients with extracranial complications underwent early surgical intervention. There was no reinfection during waiting period for surgery. All patients in the present study underwent canal wall down mastoidectomy of which 49 underwent concurrent tympanoplasty as well. Two patients had facial palsy after surgery which recovered within four weeks. One patient had bilateral complications and she underwent concurrent bilateral canal wall down mastoidectomy. Finally, timing of mastoidectomy after the management of complication can be broadly divided into three types:

\section{Interval mastoidectomy}

Mastoidectomy is performed 4 to 6 weeks after the management of complication. Patient will be under the antibiotics therapy during this period. The disadvantage of interval mastoidectomy is, during the waiting period of 4-6 weeks patient can have recurrent complication.

\section{Early mastoidectomy}

Mastoidectomy is performed as soon as they recovered from the abscess and neurosurgical drainage procedure. In the present study patient with intracranial complication underwent early mastoidectomy. There was no reinfection during waiting period for surgery.

\section{Concurrent mastoidectomy}

Mastoidectomy and neurosurgical drainage procedure is done at the same time. Current recommendations are to perform a mastoidectomy at the time of abscess drainage to remove the infectious focus.

Early mastoidectomy is the best treatment of choice for the management of squamous otitis media with complications especially in situations where concurrent mastoidectomy cannot be done due to lack of facilities, especially in developing countries. In the present study patient with intracranial complication underwent early mastoidectomy. There was no reinfection during waiting period for surgery. 


\section{References}

1. Smith JA, Danner CJ (2006) Complications of chronic otitis media and cholesteatoma. Otolaryngol Clin N Am 39: 1237-1255.

2. Viswanatha B, Naseeruddin K (2013) Neurotologic Complications of Chronic Otitis Media with Cholesteatoma. Journal of Neurology and Epidemiology 1: 20-30.

3. Viswanatha B (2007) Lateral sinus thrombosis with cranial nerves palsies. International Journal of Pediatric Otorhinolaryngology extra 2(3): 165-168.

4. Viswanatha B (2010) Bilateral concurrent mastoidectomy: A rare indication in the treatment of otitis media. International Journal of Pediatric Otorhinolaryngology Extra 5(1): 32-38.

5. Viswanatha B (2010) Otitic hydrocephalus: A report of 2 cases. Ear Nose Throat J 89(7): 34 .

6. Viswanatha B (2011) Lateral sinus thrombosis in children: A review Ear Nose Throat J 90(6): 28-33.

7. Viswanatha B (2012) Interhemispheric subdural abscess: A rare complication of atticoantral ear disease. Ear nose \& throat journal 91: 26-28.
8. Viswanatha B, Naseeruddin K (2012) Conservative management of otogenic brain abscess with surgical management of atticoantral ear disease: A Review. Indian Journal of Otolaryngology and Head \& Neck Surgery 64(2): 113-121.

9. Murthy PSN, Sukumar R, Hazarika P, Rao AD, Mukulchand Raja A (1991) Otogenic brain abscess in childhood. International Journal of Otorhinolatyngology 22: 9-17.

10. Morwani KP, Jayashankar N (2009) Single stage, transmastoid approach for otogenic intracranial abscess. The Journal of Laryngology \& Otology 123: $1216-1220$.

11. Syal R, Singh H, Duggal KK (2006) Otogenic brain abscess: management by otologist. The Journal of Laryngology \& Otology 120: 837-841.

12. Sinha Mallika, Parihar Vijay (2008) Endoscopic management of brain abscesses. Neurology India 56: 13-16.

13. Kurien M, Job A, Mathew J, Chandy M (1998) Otogenic intracranial abscess: concurrent craniotomy and mastoidectomy - changing trends in a developing country. Arch Otolaryngol Head Neck Surg 124(12): 1353-1356.

\section{(C) \\ This work is licensed under Creative Commons Attribution 4.0 License}

To Submit Your Article Click Here:

Submit Article

DOI: $10.32474 /$ SJ0.2020.05.000218

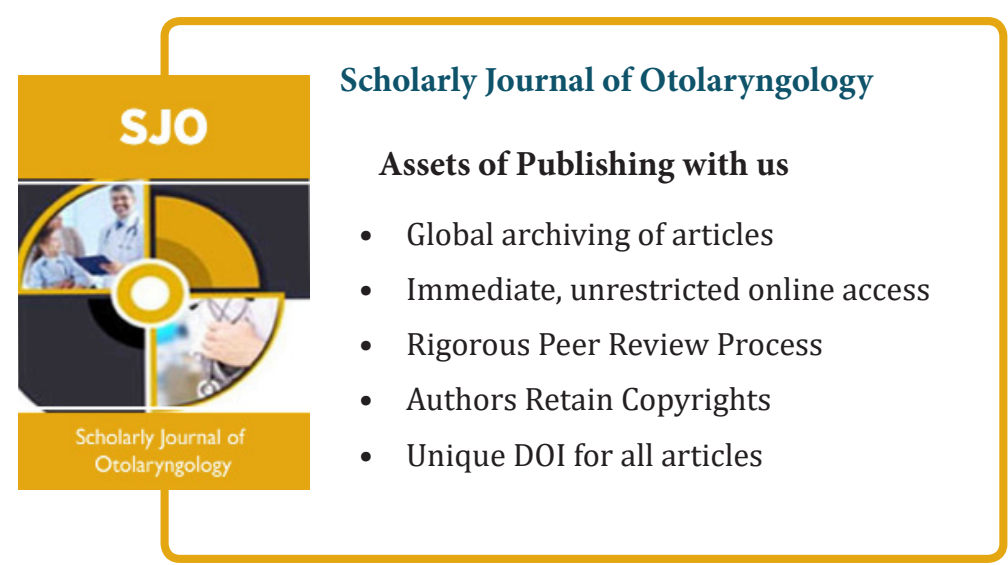

